\title{
Prospects of Trilateral Flash Cycle (TFC) for Power Generation from Low Grade Heat Sources
}

\author{
Md Arbab Iqbal, Sohel Rana, Mahdi Ahmadi, Thomas Close, Abhijit Date, Aliakbar Akbarzadeh \\ School of Mechanical and Automotive Engineering, RMIT University, Melbourne, Australia
}

\begin{abstract}
Despite the current energy crisis, a large amount of low grade heat (below $100^{\circ} \mathrm{C}$ ) is being wasted for the lack of cost effective energy conversion technology. In the case of the conventional Organic Rankine Cycle (ORC) based geothermal power stations, only about $20 \%$ of available heat can be utilised due to a technological limitation as there is a phase change in the working fluid involved during the addition of heat which decreases utilisation effectiveness of the system. Therefore, in this paper, a trilateral flash cycle (TFC) based system has been studied to find out its prospect for utilizing more power from the same heat resources as the ORC. The TFC is a thermodynamic cycle that heats the working fluid as a saturated liquid from which it starts its expansion stage. The flash expansion is achieved by feeding the saturated high-pressured liquid working fluid through a convergent-divergent nozzle at which point it undergoes a flash expansion in the low-pressure environment of the generator housing. The momentum of the working fluid is extracted via a Pelton wheel and the cycle is completed with working fluid condensation and pressurisation. The analytical comparative study between the ORC and TFC based system shows that the TFC has about $50 \%$ more power generation capability and almost zero contribution on global warming.
\end{abstract}

\section{Introduction}

Not only the depletion of conventional non-renewable energy sources i.e. fossil fuel, coal etc. but also the growing concern about the environmental changes forcing the researchers to search for alternative sustainable sources of energy as well as develop system for waste energy recovery. Though modern cutting-edge technology improved the efficiency of power generation system, there is still limitation of recovery of waste heat, specially the low-grade heat having temperature lower than $100 \mathrm{oC}$. For the recovery and conversion of low grade heat energy, the Organic Rankine Cycle (ORC) plays a major role for the simple, compact and low-cost system components with small sizing and the properties of organic fluids that can exploit low and variable temperature heat sources [1-6]. However, because of a phase change in the ORC, not only the highest temperature that the working fluid can reach is quite far from the source temperature [7] but also the lowest temperature that the heat source can reach, remains much higher than the cycle lowest temperature. These facts lead to wastage of a big portion of energy.

In the literature several different solutions have been reported to have a better match between the heat transfer curves of the heat source and the heat recovery system. The Kalina cycle (KCS) was introduced in the 1980s which converts thermal energy to mechanical power using mixture of water and ammonia as working fluid. This cycle was introduced to have a better match between the heat transfer curves by using a non- isothermal evaporation thereby reducing the average temperature difference. The layout of the Kalina cycle, however, is much more complex because of additional separators and heat exchangers which associate with additional cost as well.

Bombarda et al. [8] compared the performance of a Kalina cycle with an ORC. Despite the small advantage in terms of net mechanical power, the high working pressure of water-ammonia mixture demonstrated that this cycle was not applicable in the considered temperature range because of the high equipment costs. Pradeep Varma and Srinivas [9] found the Kalina cycle is a very low efficiency system for heat recovery from low temperature heat sources. They recommended the Organic Flash cycle (OFC) over the ORC and KCS for power generation. Baccioli et al. [6] worked with the OFC and Organic Flash Regenerative Cycle (OFRC) and observed improvement of efficiency with the OFRC as it requires a small heat exchanger and one less throttling process than that of OFC which is a source of major losses.Ho et al. $[10,11]$ worked on the Organic Flash Cycle (OFC) for power generation from low grade heat and recommended a modified 2-phase OFC which demonstrated $20 \%$ more power output, though they observed exergy destruction by the throttling valve for flash evaporation.

In 1993 Smith [12] introduced the Trilateral Flash Cycle (TFC) which is reported to be $14-85 \%$ more efficient for low grade heat recovery than the ORC [13, $14]$. 
Figure 1 represents a typical comparison between the ORC and TLC and it is clear from the figure that in the TLC, heat is transferred in a single phase working fluid which is more efficient than multiphase heat transfer like in the ORC.

Basically, the TLC has the same components as the Rankine-cycle engines but unlike the Rankine cycle, it does not evaporate the working fluid during the heating phase; instead expands it from the saturated liquid condition, as a two-phase mixture. The choice of a suitable working fluid for a given application, the feasible operating conditions/ parameters and the system configuration design, are the most essential features of any thermal system design [15-17].

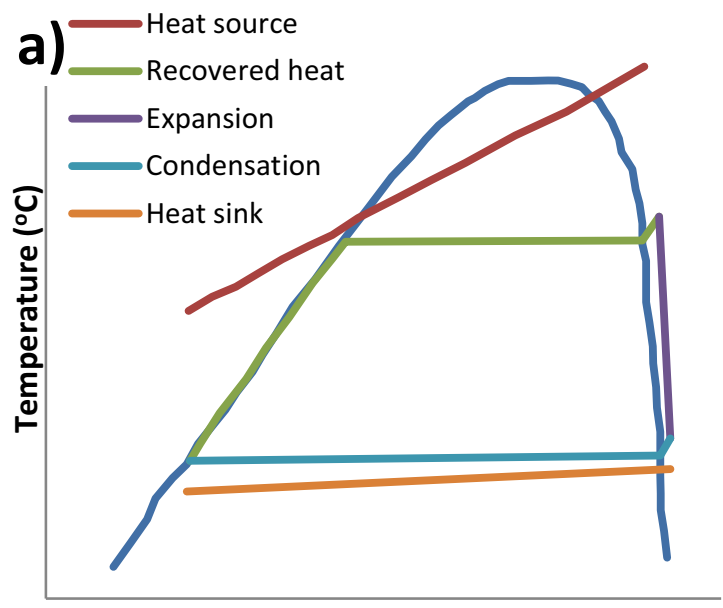

Entropy (kJ/kgK)

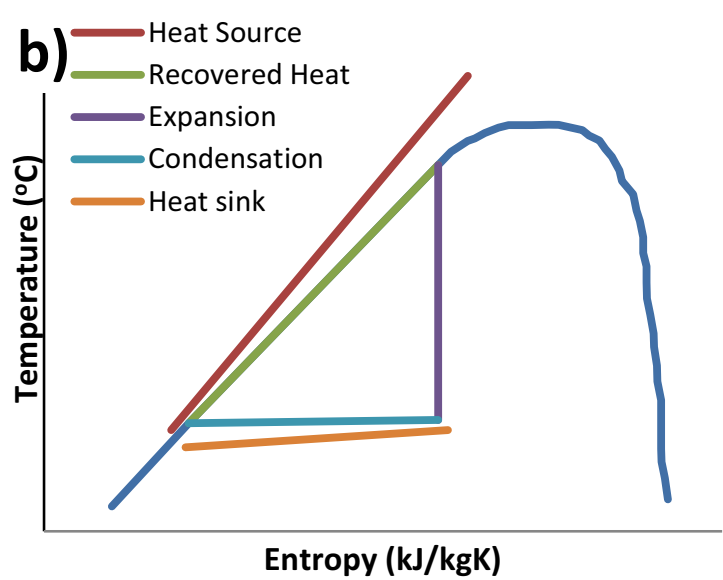

Fig. 1. a) T-s diagram for ORC, b) T-s diagram for TLC.

With the application of a suitable high molecular working fluid, the TFC power plants could recover and convert heat energy efficiently from renewable thermal sources as well as from the by product (waste heat) of numerous non-renewable sources into mechanical or electrical power. The high molecular mass allows efficient exploitation of non-isothermal single-phase heat sources for heat recovery-to-power generation, which allows the net output work of the TLC in a wide range of power capacities $[18,19]$.

The working fluid adopted for the study is isopentane because of its good thermo-physical properties (e.g. relative high critical temperature and pressure), lowcost, and a boiling point slightly above room temperature. It displays a strong positive slope on the T$\mathrm{s}$ diagram and its saturated liquid expansion tends to dry out at temperatures slightly exceeding $453 \mathrm{~K}$ [20]. More so, iso-pentane is a dry fluid, whose thermo-physical properties are well-suited for low-grade heat recovery topower generation and widely used around the world.

In this paper, we would like to study on the technological feasibility of the Trilateral Flash Cycle (TFC) for low grade heat to power generation where we can eliminate the limitations of the ORC and improve overall cycle power output. Here we considered the Birdsville Organic Rankine Cycle (ORC) geothermal power station as our case of study. Figure 2 represents the schematic layout of Birdsville geothermal power station where we can see a larger amount of heat is being wasted as the plant leaving bore water to lagoon at $80^{\circ} \mathrm{C}$ which carries about $80 \%$ of available geothermal energy. For this study, we will simulate the Birdsville ORC system as well as a TFC system for comparative performance analysis and discuss on the prospects of the TFC over the ORC.

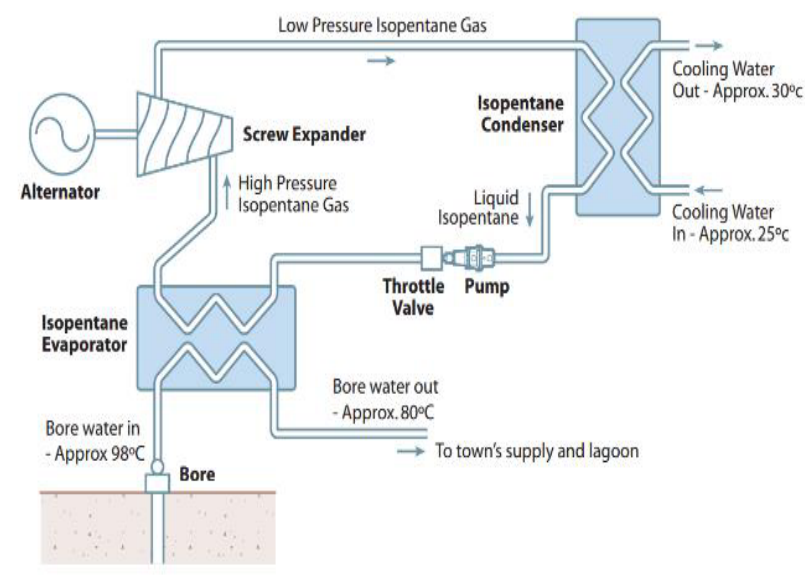

Fig. 2. ORC geothermal power station, Birdsville, Queensland, Australia.

\section{Theoretical modelling}

\section{$2.1 \mathrm{ORC}$}

ORC is the widely used power cycle for waste heat or low-grade heat to power generation. Figure 1.a shows a typical T-s diagram for ORC which complies with pumping, heating, expansion (work out) and heat rejection (condensation).

The heating load of an ORC system can be measured by,

$$
Q_{\text {in }}=\dot{m}\left(h_{3}-h_{2}\right)
$$

Where, $Q_{\text {in }}$ and $\dot{m}$ are heat-in the system and mass flow rate of the working fluid and $h_{2}$ and $h_{3}$ are enthalpy of working fluid after pump and before expander respectively. If the enthalpy of the working fluid after 
expander is $\mathrm{h}_{4}$, the work done by the expander $W_{\text {out }}$ can be expressed by,

$$
W_{\text {out }}=\dot{\mathrm{m}}\left(h_{3}-h_{4}\right)
$$

The cooling load, $Q_{\text {out }}$, and pumping power, $P_{i n}$, can be measured by,

$$
\begin{aligned}
& Q_{\text {out }}=\dot{m}\left(h_{4}-h_{1}\right) \\
& P_{\text {in }}=\Delta P \times \dot{V}
\end{aligned}
$$

Where, $h_{l}$ is the enthalpy of the working fluid at pump inlet, $\Delta P$ is the pressure difference between pump inlet and outlet and the $\dot{V}$ is the volumetic flow rate of the working fluid.

\subsection{TFC}

Figure 1.b represents the T-s diagram of a typical TFC system which is nothing but a modified ORC system where the phase change of the working fluid in the heat exchanger has been skipped. However, in TFC, the expansion is two phase flash expansion rather than single phase expansion of ORC.

In the proposed system, a convergent-divergent (CD) nozzle will aid the flash expansion in the form of high velocity jet of mixture of liquid and vapour. The isentropic quality of jet is the governing operator of the isentropic efficiency of the nozzle. To predict the performance of such kind of TFC system, let us consider, the hot water of $T_{h}$ temperature from the heat source with a flow rate of $m_{h w}$ is passing through the heat exchanger having effectiveness of $\varepsilon_{h}$ where the iso-pentane is to be heated up. If $P_{l}$ is considered as the initial condenser pressure and $T_{p l}$ is the corresponding saturated liquid isopentane temperature in the condenser, the hot iso-pentane temperature, $T_{p h}$ can be defined as,

$$
T_{p h}=\varepsilon_{h}\left(T_{h}-T_{p l}\right)+T_{p l}
$$

Maximum heating power can be defined as,

$$
H_{\text {max }}=m_{h w} C_{p w}\left(T_{h}-T_{p h}\right) \varepsilon_{h}
$$

Here, $C_{p w}$ is the specific heat of liquid hot water. The maximum iso-pentane flow rate can be defined as,

$$
m_{p}=\frac{H_{\max }}{\left(T_{p h}-T_{p l}\right) C_{p p}}
$$

The isentropic quality at the nozzle exit can be defines as,

$$
x_{4}=\frac{S_{f, 3}-S_{f, 4}}{S_{f g, 4}}
$$

Here, $S_{f, 3}, S_{f, 4}$ and $S_{f g, 4}$ are the entropy of the fluid at the nozzle inlet, the entropy of the saturated liquid at nozzle exit conditions and the entropy difference of saturated liquid and vapour at nozzle exit, respectively. The isentropic enthalpy at the nozzle exit can be defines as,

$$
h_{4}=h_{f, 4}+x_{4} h_{f g, 4}
$$

Here, $h_{f, 4}$ and $h_{f g, 4}$ are the enthalpy of the fluid at the nozzle exit and the enthalpy difference of saturated liquid and vapour at nozzle exit, respectively.
Now, the isentropic nozzle exit velocity (neglecting inlet velocity and change in potential energy) can be given by,

$$
u_{4}=\sqrt{2\left(h_{3}-h_{4}\right)}
$$

The force developed by the nozzle can be given by,

$$
F_{n}=m_{p} u_{4}
$$

The work done or power developed by the nozzle $\mathrm{W}_{\text {out, } \mathrm{N}}$ can be expressed by,

$$
\begin{gathered}
W_{\text {out }, N}=0.5 \times \dot{\mathrm{m}} \times u_{4}{ }^{2} \\
\text { Or, } \\
W_{\text {out }, N}=\dot{m}\left(h_{3}-h_{4}\right)
\end{gathered}
$$

\section{Proposed TFC system}

The TFC implements a heat to power conversion via heat transfer to a pressurised working liquid of low boiling point which is then injected at an optimum temperature (saturation temperature) through a nozzle into a turbine fed generator thus outputting usable electrical energy. The used liquid then returns to a reservoir before it is condensed and forced through the same process again via a high-pressure pump.

\section{Prospect analysis}

Here we will analyse the prospect of the TFC over the ORC on the basis of net power generation, wastage of heat energy, different component size and environmental impact. From figure 3, the combine T-s diagram of the ORC and TFC, we can see that the TFC has more power output capability than that of the ORC for the same heat source and heat sink though the TFC has a lower thermodynamic efficiency. This phenomenon can be described by the term utilization of energy (UOE) which is the product of co-efficient of utilization (COU) and the efficiency of the thermodynamic working cycle. COU is the ratio of maximum possible available energy that can be recovered by the cycle to the maximum available recoverable energy that is being wasted. If maximum heat source temperature is $T_{\max }$ and heat sink temperature is $T_{\min }$ and the temperature of the heat carrier leaving the system is $T_{\text {out }}$, the COU can be expressed by the following equation,

$$
\operatorname{COU}_{\text {system }}=\frac{\Delta T_{\text {system }}}{\Delta T_{\max }}
$$

Where,

and

$$
\Delta T_{\text {system }}=T_{\max }-T_{\text {out }}
$$

$$
\Delta T_{\max }=T_{\max }-T_{\min }
$$

And if the system thermodynamic is efficiency is $\eta$ system, the UOE can be expressed by the following equation,

$$
U O E_{\text {system }}=C O U_{\text {system }} \times \eta_{\text {system }}
$$

Figure 4 represents the variation of UOE of the ORC and TFC based system for different heat source and heat 
sink temperature. For the ORC system, a sharp drop of UOE observed for heat source temperature $92^{\circ} \mathrm{C}$ to $90^{\circ} \mathrm{C}$ as there were some changes in constrains to maintain a defined minimum pressure difference $(1.7$ bar) across the expender. It is also clear from figure 4 that as the heat source temperature decreases, the UOE of both systems falls down and below $90^{\circ} \mathrm{C}$, the $\mathrm{ORC}$ system is not economically viable.

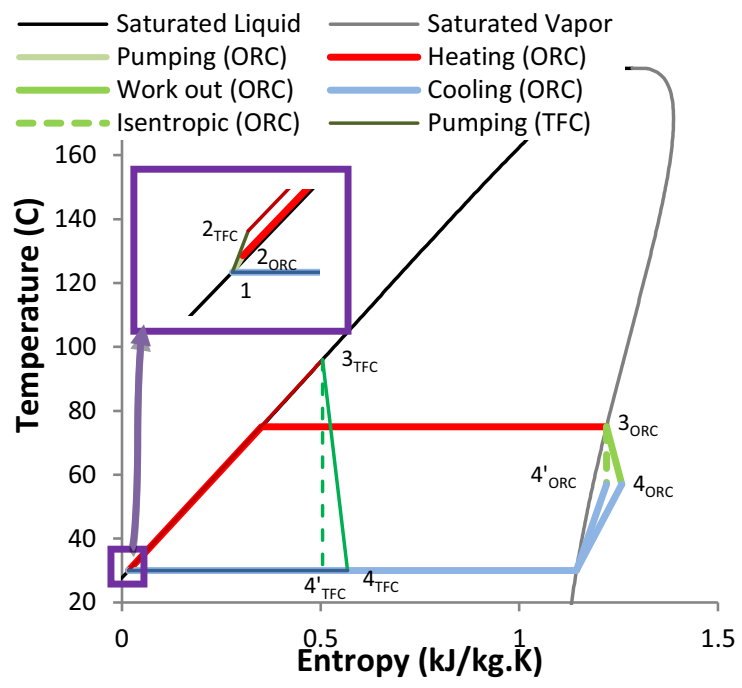

Fig. 3. T-s diagram for TFC and ORC.

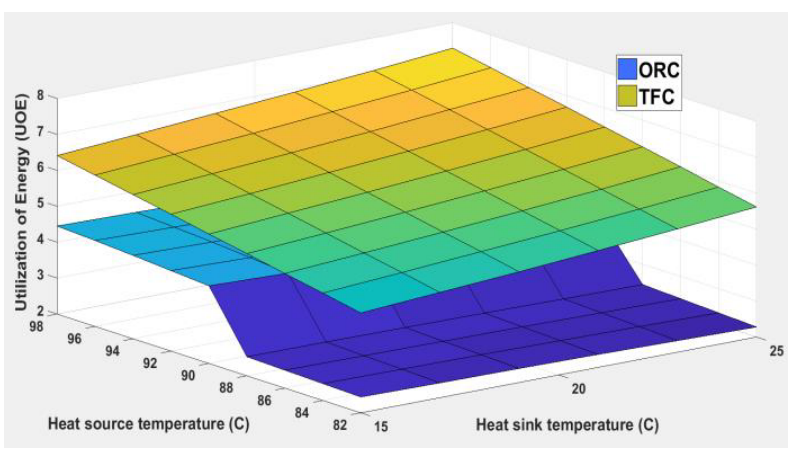

Fig. 4. UOE for ORC and TFC for different heat source and heat sink.

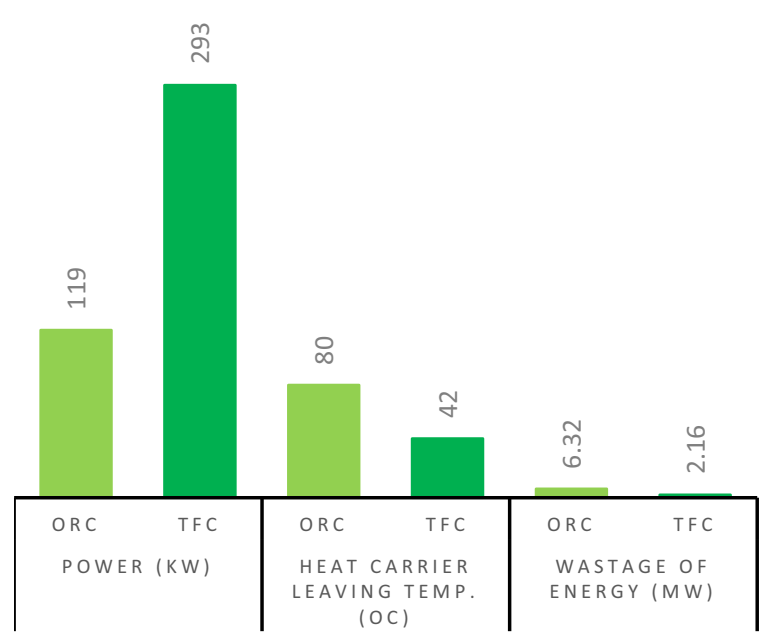

Fig. 5. Comparative performance of TFC and ORC.
Figure 5 shows that in using the TFC instead of the ORC, $174 \mathrm{~kW}$ more net power can be produced from the existing Birdsville geothermal resources. Moreover, the TFC system can facilitate to cool down the system leaving hot water temperature close to ambient temperature and reduces overall wastage of energy.

Figure 6 represents the comparison of different system component sizing for the ORC and TFC. It is obvious that the TFC system requires a larger heat exchanger and condenser as it deals with larger amounts of heat than that of the ORC, however, it also requires more pumping power which basically reflects more initial investment which can be compensated by producing additional power. The power developed by the proposed TFC system is directly proportional to the nozzle isentropic efficiency which is presented in figure 7 . Though it not practical to achieve $100 \%$ efficiency, about $80 \%$ efficiency in the nozzle can develop twice as much power than the ORC based system and achieving such a high level of efficiency in the nozzle is hard but not impossible. However, a 65\% efficient nozzle which can easily be achieved can produce about $50 \%$ more power than the ORC.

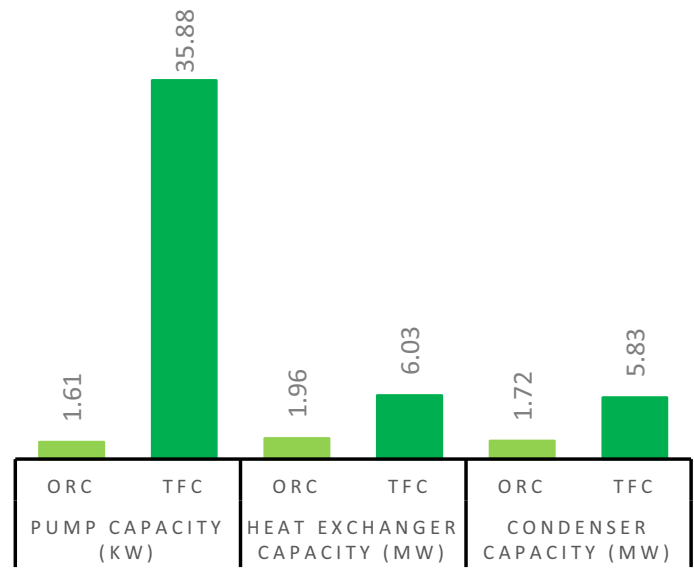

Fig. 6. Comparative component sizing for TFC and ORC.

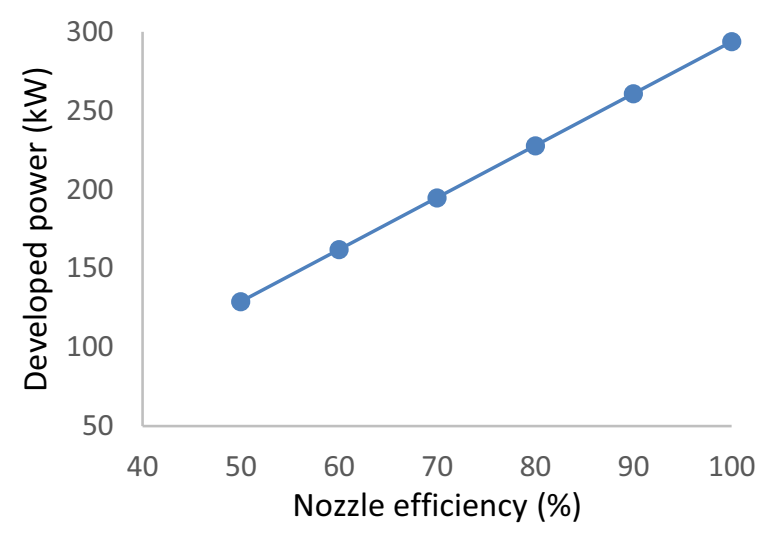

Fig. 7. Variation of developed power with nozzle efficiency.

\section{Conclusion}

In context of the current energy crisis, wasting energy especially low-grade heat $\left(<100^{\circ} \mathrm{C}\right)$ is the major concern 
and the TFC system can be a promising technology for these waste heat recoveries and power generation. The analytical analysis of this paper shows that replacement of the ORC based current Birdsville geothermal power generation station by a TFC based system can produce more power. The results of this study can be summarised as follows,

$>$ About $50 \%$ more power can be produced by the TFC based system than the ORC based system

$>$ for the same heat source and heat sink conditions.

$>$ The TFC system can utilise up to $70 \%$ of available thermal power.

$>$ The TFC system can produce a significant amount of power from very low temperature

$>$ heat sources (below $80 \mathrm{oC}$ ) where with the ORC it is not feasible.

$>$ The TFC system allows the heat carrier to leave the system very close to ambient temperature that contribute almost zero to global warming.

\section{References}

1. Liu, B.-T., K.-H. Chien, and C.-C. Wang, Effect of working fluids on organic Rankine cycle for waste heat recovery. Energy, 2004. 29(8): p. 1207-1217.

2. Jing, L., P. Gang, and J. Jie, Optimization of low temperature solar thermal electric generation with Organic Rankine Cycle in different areas. Applied Energy, 2010. 87(11): p. 3355-3365.

3. Pei, G., J. Li, and J. Ji, Analysis of low temperature solar thermal electric generation using regenerative Organic Rankine Cycle. Applied Thermal Engineering, 2010. 30(8): p. 998-1004.

4. Roy, J.P., M.K. Mishra, and A. Misra, Parametric optimization and performance analysis of a waste heat recovery system using Organic Rankine Cycle. Energy, 2010. 35(12): p. 5049-5062.

5. Lakew, A.A. and O. Bolland, Working fluids for low-temperature heat source. Applied Thermal Engineering, 2010. 30(10): p. 1262-1268.

6. Baccioli, A., M. Antonelli, and U. Desideri, Technical and economic analysis of organic flash regenerative cycles (OFRCs) for low temperature waste heat recovery. Applied Energy, 2017. 199: p. 69-87.

7. Nguyen, T.Q., J.D. Slawnwhite, and K.G. Boulama, Power generation from residual industrial heat. Energy Conversion and Management, 2010. 51(11): p. 2220-2229.

8. Bombarda, P., C.M. Invernizzi, and C. Pietra, Heat recovery from Diesel engines: A thermodynamic comparison between Kalina and ORC cycles. Applied Thermal Engineering, 2010. 30(2): p. 212219.
9. Varma, G.V.P. and T. Srinivas, Power generation from low temperature heat recovery. Renewable and Sustainable Energy Reviews, 2017. 75: p. 402-414.

10. Ho, T., S.S. Mao, and R. Greif, Comparison of the Organic Flash Cycle (OFC) to other advanced vapor cycles for intermediate and high temperature waste heat reclamation and solar thermal energy. Energy, 2012. 42(1): p. 213-223.

11. Ho, T., S.S. Mao, and R. Greif, Increased power production through enhancements to the Organic Flash Cycle (OFC). Energy, 2012. 45(1): p. 686695.

12. Smith, I.K., Development of the trilateral flash cycle system Part 1: fundamental consideration. Proceedings of the Institution of Mechanical Engineers, Part A: Journal of Power and Energy, 1993. 207(3): p. 179-194

13. Smith, I., N. Stosic, and C. Aldis, Trilateral flash cycle system a high efficiency power plant for liquid resources. Proceedings World Geothermal Congress 1995, 1995: p. 2109.

14. Fischer, J., Comparison of trilateral cycles and organic Rankine cycles. Energy, 2011. 36(10): p. 6208-6219.

15. Dincer, I. and H. Al-Muslim, Thermodynamic analysis of reheat cycle steam power plants. Fuel and Energy Abstracts, 2002. 43(4): p. 264

16. Chen, H., et al., A supercritical Rankine cycle using zeotropic mixture working fluids for the conversion of low-grade heat into power. Energy, 2011. 36(1): p. 549-555.

17. Sahin, A.Z., et al., Special Issue: Thermodynamic Optimization, Exergy Analysis, and Constructal Design. Arabian Journal for Science and Engineering, 2013. 38(2): p. 219-219.

18. Invernizzi, C., P. Iora, and P. Silva, Bottoming micro-Rankine cycles for micro-gas turbines. Applied Thermal Engineering, 2007. 27(1): p. 100110.

19. Baral, S. and K.C. Kim, Thermodynamic Modeling of the Solar Organic Rankine Cycle with Selected Organic Working Fluids for Cogeneration. Distributed Generation \& Alternative Energy Journal, 2014. 29(3): p. 7-34.

20. Smith, I.K. and R.P.M. da Silva, Development Of The Trilateral Flash Cycle System Part 2: Increasing Power Output With Working Fluid Mixtures. Proceedings of the Institution of Mechanical Engineers, Part A: Journal of Power and Energy 1990-1996 1994. 208: p. 135-144. 